\title{
Integration of single and dual command operations in non-traditional warehouse design
}

\author{
Marco Bortolini $^{1}$ [D $\cdot$ Francesco Gabriele Galizia $^{1}$ (D) $\cdot$ Mauro Gamberi $^{1}$ (D) $\cdot$ Francesco Gualano $^{1}$ (D)
}

Received: 3 May 2020 / Accepted: 9 October 2020 / Published online: 28 October 2020

(C) The Author(s) 2020

\begin{abstract}
Non-traditional warehouses rise as effective solutions to shorten the travelled distances to store and retrieve unit loads, adding aisles crossing the parallel racks. Multiple warehouse configurations are proposed by the literature discussing the enhancements toward standard layouts. In previous contributions, the authors introduced the diagonal cross-aisle model, concluding about its positive impact on the handling performances under single command operations. This paper extends the previous works, integrating dual command operations, through an original analytic model supporting the design of non-traditional warehouses with a couple of symmetric straight diagonal cross-aisles and random storage assignment strategy. The closed-form expressions to compute the expected cycle travel distances are provided, optimising the aisle position. An industrial case study applies the model, getting distance savings ranging from 11 to $17 \%$, compared to standard layout and further considering the loss of storage space due to the presence of the additional aisles.
\end{abstract}

Keywords Non-traditional warehouse $\cdot$ Warehouse design $\cdot$ Diagonal cross-aisle $\cdot$ Dual command operations $\cdot$ Travel distance model

\section{Introduction}

Warehouses represent a capstone of supply chain management [1]. Unit-load (UL) storage systems are the most diffuse solutions to receive, store and ship products into single units moved using pallets [2]. Industrial companies adopt warehouses to smooth the dynamic market fluctuations, getting significant benefits, e.g. service level increase, time-tomarket reduction, etc. [3, 4]. On the other hand, warehouses do not add value to the products. Handling and storage are muda from the lean production viewpoint [5]. Within warehouse management, the most time-consuming activities are the UL storage and retrieval (S/R) actions. This is due to the increase of the warehouse dimensions, bottlenecks and congestions, making the travel time a key factor to manage [6]. The warehouse layout is a critical asset to increase efficiency, reducing the expected travelled distance and, consequently,

Marco Bortolini

marco.bortolini3@unibo.it

1 Department of Industrial Engineering, Alma Mater Studiorum University of Bologna, Viale del Risorgimento, 2,

40136 Bologna, Italy the overall inbound logistic cost [7]. According to Rouwenhorst [8] and Gu et al. [9], the layout design problem deals with the effective definition of a set of decisional variables crossing three decisional levels, i.e. strategic, tactical and operative. In particular, the key decisional areas define:

- The overall size of the warehouse, setting the storage capacity and the floor space;

- The automation level of the S/R system;

- The shape factor, i.e. ratio between the two plant area dimensions;

- The number of vertical levels;

- The number and the position of the pickup and delivery (P\&D) points;

- The aisle number and positioning;

- The assignment policy of the items to the bays.

These cross-dependent features univocally define the warehouse configuration, i.e. layout, and they constitute the input of mathematical models to predict the warehouse operation performances [10]. Pioneering contributions and relevant reviews in the field are in $[9,11-18]$.

The recent literature explores new warehouse layouts, called non-traditional warehouses (NTWs) in the following, 
in which some of the typical constraints of the standard warehouse layout are relaxed to shortening the travelled distances. NTWs may include additional aisles and/or upgrades in the rack positioning. Among them, in 2015, Bortolini et al. [19] introduced the diagonal cross-aisle model based on the inclusion of one or multiple couples of straight aisles crossing the racks diagonally with no changes in the rack positioning respect to the standard reference layout, i.e. parallel vertical racks (Fig. 1).

Adopting this layout, this paper extends the previous design model proposed by Bortolini et al. [19], integrating single and dual command operations for the UL S/R. The closedform expressions to compute the expected cycle travel distances are provided as the basis to optimise the diagonal cross-aisle position. As far as the author knowledge, despite analytic models to get the single command cycle distance exist for multiple NTW layouts, the inclusion of dual command operations and the integration of single and dual command cycles are rare and, additionally, still not provided for the considered NTW configuration.

According to the introduced background and purposes, the remainder of the paper is organised as follows. Section 2 reviews the literature on NTWs under single and dual command operations, while Section 3 states the problem, lists the model hypotheses and the analytic models to get the expected single and dual command cycle distances. Section 4 optimises the NTW layout further discussing the benefits compared to standard warehouses, i.e. benchmark. Section 5 applies the model to an industrial case study, while Section 6 concludes the paper with final remarks and future research opportunities.

\section{Literature review}

The literature on the design and management of UL warehouses is wide and multi-attribute, while past and recent reviews present the current state-of-the-art and future perspectives [9, 16-18]. As introduced, warehouse design tackles a wide set of areas to manage, e.g. sizing, layout planning, equipment selection, UL assignment, etc. [9], while diffuse

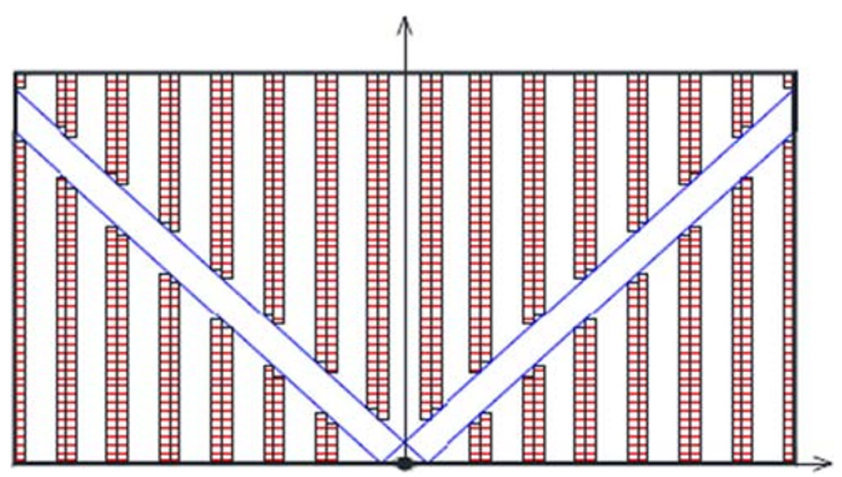

Fig. 1 Diagonal cross-aisle layout [19] metrics to assess and compare the design models focus on the handling performances, as technical parameters affecting the daily management, the service level and the storage costs [7].

NTWs rose as feasible alternatives to standard layouts to reduce the travelling distances in UL S/R operations. White [20] was a pioneer in this field proposing a NTW having a radial aisle structure. Gue and Meller [2] introduced Fishbone and Flying-V layouts, becoming top of attention NTW configurations. The former layout presents two $45^{\circ}$ oriented crossaisles and orthogonal couples of racks at its two sides; the latter layout includes two curve cross-aisles with parallel vertical racks. Pohl et al. [6] showed the savings coming from the adoption of the Fishbone layout with dual command operations and random storage assignment strategy. In a later contribution, the same authors extend their analysis to full turnover-based assignment strategy [21]. Jiang et al. [22] proposed an improved Fishbone layout by changing boundary conditions, while Cardona et al. [23] compared the performance of Fishbone and standard layouts considering different industrial contexts. Furthermore, Öztürkoğlu et al. [24] introduced three new NTW layouts characterised by an increasing number of cross-aisles, optimising the warehouse size, while Mesa [25] proposed a new diamond layout using random and class-based storage assignment under single command operations. Considering multiple P\&D points, several contributions [26-32] upgraded previous design models, while Clark and Meller [33] investigated the impact of the vertical travel distances to reach the bays. Bortolini et al. [19], Accorsi et al. [34] and Bortolini et al. [35] introduced the aforementioned diagonal cross-aisle layout. This layout is at the edge between Fishbone and Flying-V configurations, i.e. two optimally oriented straight symmetric cross-aisles departing from the central P\&D point with no changes in the rack positioning (Fig. 1).

Table 1 classifies the last decade literature contributions according to three relevant metrics, i.e. (1) the adopted layout, (2) the UL S/R operation mode and (3) the UL assignment policy.

Concerning metric (1), Fishbone and Flying-V are top of attention NTW layouts, inspiring other configurations, e.g. diagonal cross-aisle. About metric (2), the most of the literature considers single command operations. Pohl et al. [21, 36, 37] and Galvez and Ting [38] studied dual command operations and early approaches to integrate single and dual command cycles stating about the relevance of further efforts on this point. Finally, on metric (3) random storage assignment of the ULs in the bays is used for the most of the models despite full turnover-based and class-based storage strategies are used by some authors to enhance the operation performances [39-45].

Globally, the literature highlights the lack of studies providing models integrating single and dual command operations in NTWs different from the Fishbone layout. Focusing 
Table 1 Literature classification of NTWs

\begin{tabular}{lllll}
\hline Year & Author(s) & Layout & S/R operations & Assignment policy \\
\hline 2009 & Gue et al. & Fishbone + Flying-V & Single command & Random \\
2009 & Pohl et al. & Fishbone & Dual command & Random \\
2011 & Pohl et al. & Fishbone & Single and dual command & Random + Full turnover based \\
2012 & Öztürkoğlu et al. & Chevron + Leaf + Butterfly & Single command & Random \\
2012 & Gue et al. & Flying-V (modified) & Single command & Random \\
2012 & Galvez and Ting & Fishbone & Single and dual command & Random \\
2012 & Cardona et al. & Fishbone & Single command & Random \\
2013 & Clark and Meller & Fishbone + Flying-V & Single command & Random \\
2013 & Jiang et al. & Fishbone (modified) & Single command & Random \\
2014 & Öztürkoğlu et al. & Chevron & Single command & Random \\
2015 & Bortolini et al. & Diagonal cross-aisle & Single command & Random \\
2016 & Mesa & Diamond & Single command & Random + Class-based storage \\
2018 & Öztürkoğlu et al. & Chevron & Single command & [23] \\
2018 & Accorsi et al. & Diagonal cross-aisle & Single command & Random \\
2019 & Kocaman et al. & Chevron (modified) & Single command & Class-based storage \\
2019 & Bortolini et al. & Diagonal cross-aisle & Single command & Random \\
\hline
\end{tabular}

on the diagonal cross-aisle layout, the next Section 3 fills this gap revising the single command model and fully describing the dual command model and the integration between the two.

\section{Single and dual command model for diagonal cross-aisle layout}

The proposed model considers the NTW layout of Fig. 1 to compute the single and dual command cycle distances. Figure 2 presents the reference schematics in the normalised dimensionless space.

According to the past literature, the following set of assumptions and notations are used $[2,19]$ :

1- UL warehouse with single and dual command cycles;

2- The P\&D point is located in the lower centre of the front, representing the origin of axes;

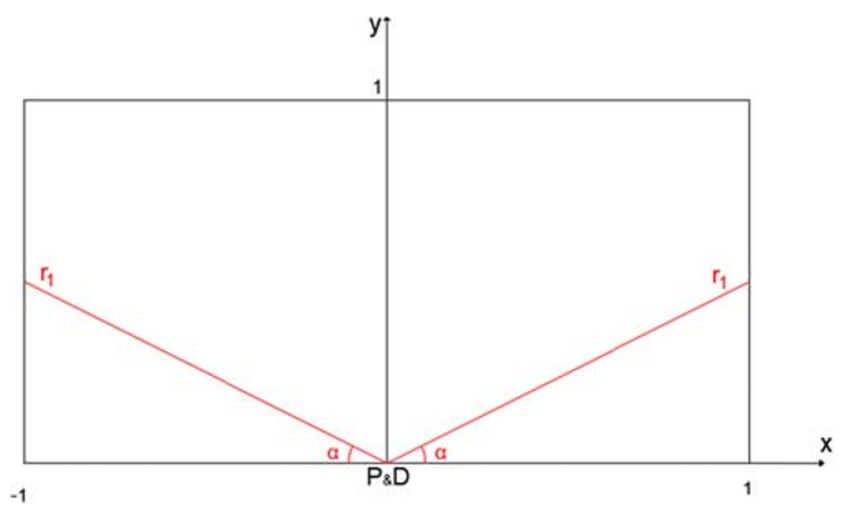

Fig. 2 Schematic of the normalised NTW layout
3- The so-called shape factor is equal to two so that a squared plant area is present for each half of the storage system;

4- In the normalised dimensionless space, the storage system area is $A=2$ with $x \in[-1,1]$ and $y \in[0,1]$;

5- A couple of symmetric straight diagonal cross-aisles is present, i.e. the red lines of Fig. 2, and univocally identified by the angle $\alpha$, with $0 \leq \alpha \leq \frac{\pi}{4}$, and $r_{1}: y=\operatorname{abs}(x$. $\tan \alpha$ ), where $\operatorname{abs}(\cdot)$ is the absolute value function;

6- The storage assignment policy is random, all the items have equal probability of being $\mathrm{S} / \mathrm{R}$;

7- The ULs have the same dimensions and they are allocated continuously into the racks;

8- The movements along the $z$-axis are neglected;

9- The return policy to access the aisles is used.

Finally, for single command cycles, Bortolini et al. [19] discussed on the possibility of adding more than a couple of symmetric straight diagonal cross-aisles to increase the distance savings. The authors concluded that the inclusion of a couple of diagonal cross-aisle is a good trade-off among distance savings, loss of storage space and layout complexity in the case of mid-size warehouses. These conclusions, logically extended to the present context including dual command cycles, drove the adopted assumption 5 .

\subsection{Single command cycles}

Single command cycles start and return at the $P \& D$ point after a storage or a retrieval action $[1,3,6,7,9]$. Consequently, given a storage location to connect, the total length of the 
single command cycle is two times the distance to connect the P\&D point to the storage location. Bortolini et al. [19] widely discussed the single command distance model for the NTW layout of Fig. 2. Three zones and travel distance models rise, as depicted in Fig. 3.

A point in Zone 1 is accessible by travelling horizontally along the front of the storage system and, then, vertically up to the storage location, while points in Zone 2 and 3 are accessible by travelling through the diagonal cross-aisle and, then, vertically, down (Zone 2) or up (Zone 3 ) reaching the storage bay. Zone 1 and 2 are divided by the line $r_{2}: y=\operatorname{abs}(x \cdot \tan \phi)$, called iso-distance line in [19]. The iso-distance line is the locus of points whose distance from the P\&D point, choosing the bottom front cross-aisle and up the picking aisle, i.e. as in Zone 1, or travelling along the diagonal cross-aisle and down the picking aisle, i.e. as in Zone 2, are the same. Analytically:

$\tan \phi=\frac{1+\sin \alpha-\cos \alpha}{2 \cdot \cos \alpha}$

The distance functions to connect the P\&D point to a generic point $P(x, y)$ inside the three zones are in Eqs. 2 and 3 [19].

$$
\begin{aligned}
f_{Z_{1}}^{S C}(x, y, \alpha)=\operatorname{abs}(x)+y & \\
f_{Z_{2}}^{S C}(x, y, \alpha)=f_{Z_{3}}^{S C}(x, y, \alpha)= & \frac{\operatorname{abs}(x)}{\cos \alpha} \\
& +\operatorname{abs}(\operatorname{abs}(x) \cdot \tan \alpha-y)
\end{aligned}
$$

where the subscripts identify the zone and $S C$ refers to the single command cycle. According to Fig. 3, the three zones are defined as follows [19]:

$$
\begin{aligned}
Z_{1} & =\left\{\begin{array}{c}
-1 \leq x \leq 1 \\
0 \leq y \leq x \cdot \tan \phi
\end{array}\right. \\
& =\left\{\begin{array}{c}
-1 \leq x \leq 1 \\
x \cdot \tan \phi<y \leq x \cdot \tan \alpha
\end{array} \quad Z_{3}=\left\{\begin{array}{c}
-1 \leq x \leq 1 \\
y>x \cdot \tan \alpha
\end{array}\right.\right.
\end{aligned}
$$

To compute the average single command distance, $E^{S C}(\alpha)$, the Integral Mean Value Theorem in Eq. 5 is used:

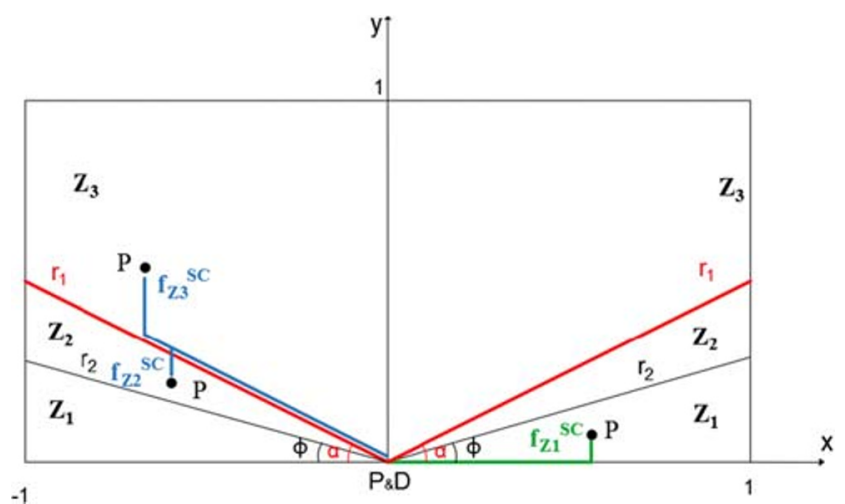

Fig. 3 Zones and travel distances for the single command model, $f_{Z_{i}}^{S C}$
$E^{S C}(\alpha)=\frac{2}{A} \cdot \sum_{i=1}^{3} \int_{Z_{i}} f_{Z_{i}}^{S C}(x, y, \alpha) d Z_{i}$

The average single command distance depends on the diagonal cross-aisle position, identified by $\alpha$ angle. Bortolini et al. [19] optimised this position, minimising $E^{S C}(\alpha)$ numerically, getting an optimal orientation of about $\alpha_{\text {opt }}^{S C}=34.85^{\circ}$.

In the following Section 3.2, the model extension to include dual command cycles is discussed before comparing and best balancing the diagonal cross-aisle position in the case of a mix of single and dual command operations.

\subsection{Dual command cycles}

Dual command cycles join a storage and a retrieval action within the same warehouse access. They are made of a single command cycle plus the so-called travel between, connecting the drop-off to the next pickup position $[1,3,6,7,9]$.

Given the proposed NTW layout, previous Eqs. 2 and 3 allow calculating the distances for the single command paths, while the travel between distance is a function of the starting point, i.e. drop-off, and the end point, i.e. pickup, positions. Despite single command cycles start and finish at the P\&D point (origin of axes), the travel between distance has no fix point of origin and destination so that an extension of the analytic models proposed by the literature is necessary [8].

\subsubsection{Travel between paths}

Let $P_{1}\left(x_{1}, y_{1}\right)$ and $P_{2}\left(x_{2}, y_{2}\right)$ be two points inside the NTW to connect by a travel between path. Because of the problem is symmetric, the distance between $P_{1}$ and $P_{2}$ is the same as the distance between $P_{2}$ and $P_{1}$. Depending on the point reciprocal positions, the shortest distance to connect them changes, further taking advantage on the diagonal cross-aisle. Five reference cases appear. They are depicted in Fig. 4, while Eqs. 6 to 10 present the analytic expressions of the correspondent travel between distance functions, $f_{Z_{j}}^{T B}\left(x_{1}, y_{1}, x_{2}, y_{2}, \alpha\right)$. The subscript $j=a, \ldots, e$ indicates the case and, for each case, the travel distances are exemplified in Fig. 4.

$f_{Z_{a}}^{T B}\left(x_{1}, y_{1}, x_{2}, y_{2}, \alpha\right)=\operatorname{abs}\left(x_{2}-x_{1}\right)+y_{1}+y_{2}$

$f_{Z_{b}}^{T B}\left(x_{1}, y_{1}, x_{2}, y_{2}, \alpha\right)=\operatorname{abs}\left(x_{2}-x_{1}\right)+2-y_{1}-y_{2}$

$f_{Z_{c}}^{T B}\left(x_{1}, y_{1}, x_{2}, y_{2}, \alpha\right)=\operatorname{abs}\left(\operatorname{abs}\left(x_{1}\right) \cdot \tan \alpha-y_{1}\right)$

$$
\begin{aligned}
& +\operatorname{abs}\left(\frac{x_{2}}{\cos \alpha}-\frac{x_{1}}{\cos \alpha}\right) \\
& +\operatorname{abs}\left(\operatorname{abs}\left(x_{2}\right) \cdot \tan \alpha-y_{2}\right)
\end{aligned}
$$




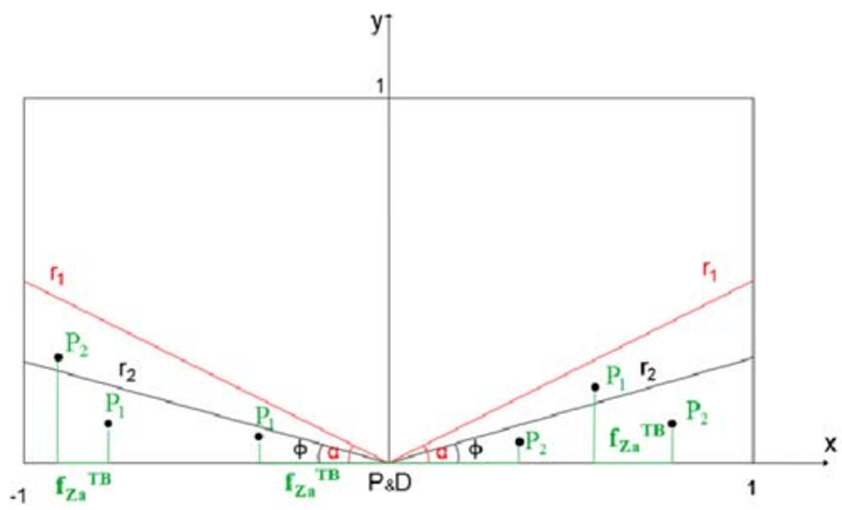

(a)

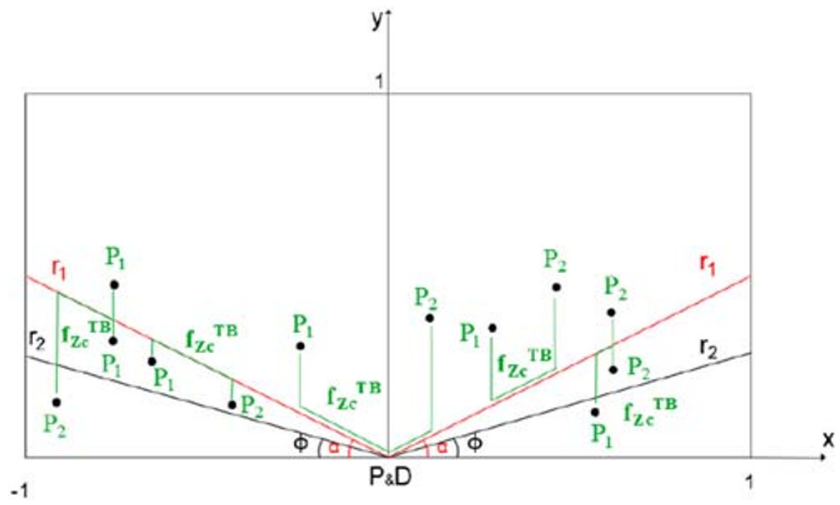

(c)

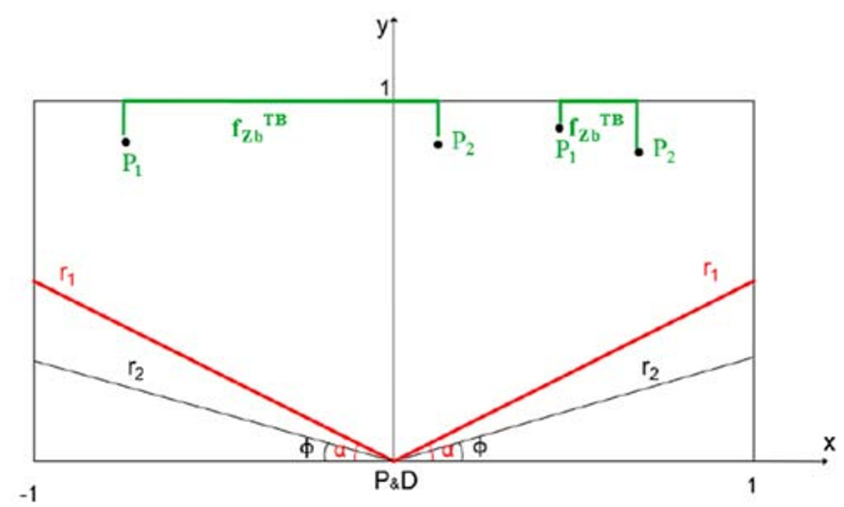

(b)

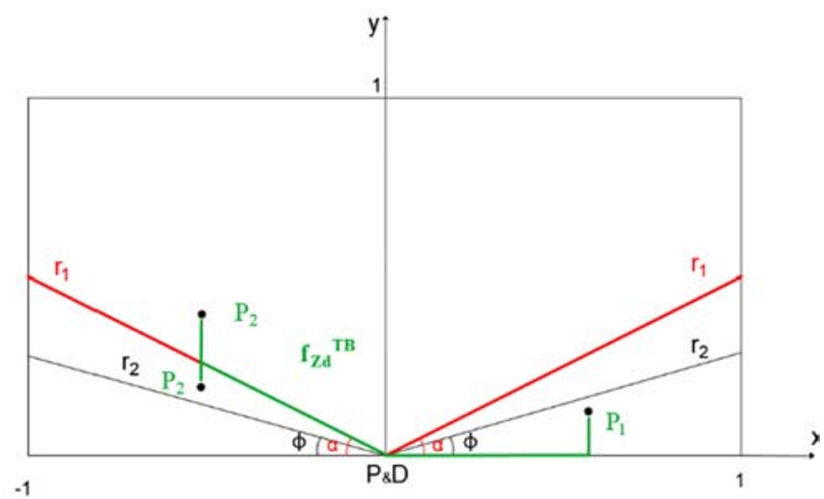

(d)

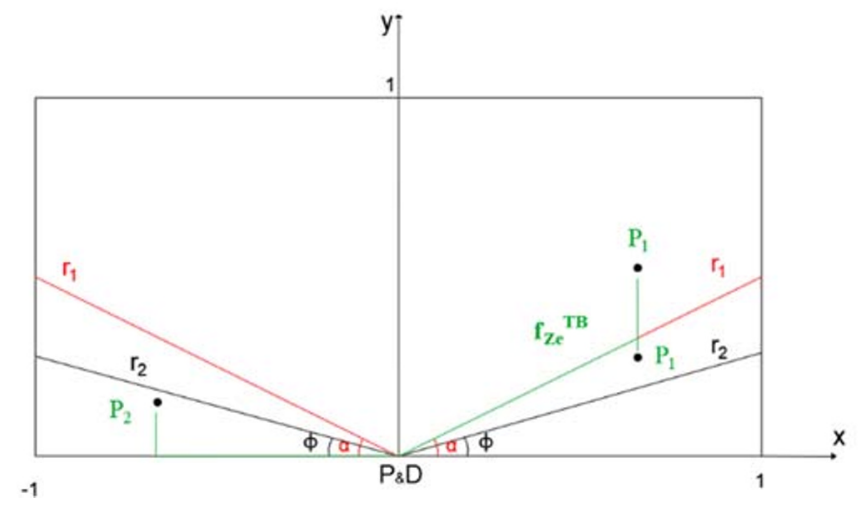

(e)

Fig. 4 Travel between reference cases and distances, $f_{Z_{j}}^{T B}$

$$
\begin{aligned}
f_{Z_{d}}^{T B}\left(x_{1}, y_{1}, x_{2}, y_{2}, \alpha\right)= & \operatorname{abs}\left(\operatorname{abs}\left(x_{2}\right) \cdot \tan \alpha-y_{2}\right) \\
& +\operatorname{abs}\left(\frac{x_{2}}{\cos \alpha}-x_{1}\right)+y_{1} \\
f_{Z_{e}}^{T B}\left(x_{1}, y_{1}, x_{2}, y_{2}, \alpha\right)= & \operatorname{abs}\left(\operatorname{abs}\left(x_{1}\right) \cdot \tan \alpha-y_{1}\right) \\
& +\operatorname{abs}\left(\frac{x_{1}}{\cos \alpha}-x_{2}\right)+y_{2}
\end{aligned}
$$

Extending Eq. 4, for each travel between function, $f_{Z_{j}}^{T B}\left(x_{1}\right.$ $\left., y_{1}, x_{2}, y_{2}, \alpha\right)$, its zone of applicability, $Z_{j}$, should be defined. $Z_{j}$ is the set of the reciprocal positions of the starting point, i.e. drop-off point $P_{1}\left(x_{1}, y_{1}\right)$, and the end point, i.e. pickup point $P_{2}\left(x_{2}, y_{2}\right)$, of the travel between path making $f_{Z_{j}}^{T B}\left(x_{1}, y_{1}, x_{2}\right.$ $\left., y_{2}, \alpha\right)$ the shortest distance function. Because each point is defined in the normalised area $A$, each zone of applicability is a partition of the $A \times A$ hyperspace, i.e. $\cup_{j=a}^{e} Z_{j}=A \times A$ and $Z_{j} \cap Z_{k}=\varnothing, j \neq k$. The analytic formulations of $Z_{j}$ for the five 
reference cases, i.e. $j=a, \ldots, e$, are piecewise defined and detailed in Appendix.

\subsubsection{Dual command cycle model}

Dual command cycles join a single command cycle and a travel between path. The two points $P_{1}\left(x_{1}, y_{1}\right)$ and $P_{2}\left(x_{2}, y_{2}\right)$, i.e. drop-off and pickup point, univocally defining the travel between path, define, also, the dual command cycle. Each of them, separately, also defines the single command distance to connect to the P\&D point. Analytically, the dual command travel distance comes from the sum of three addenda, (1) the single command travel distance, $f_{Z_{i}}^{S C}\left(x_{1}, y_{1}, \alpha\right)$, connecting the $\mathrm{P} \& \mathrm{D}$ point to the drop-off point, $P_{1},(2)$ the travel between distance connecting $P_{1}$ to $P_{2}, f_{Z_{j}}^{T B}\left(x_{1}, y_{1}, x_{2}, y_{2}, \alpha\right)$, and (3) the single command travel distance, $f_{Z_{i}}^{S C}\left(x_{2}, y_{2}, \alpha\right)$ to move back to the P\&D point starting from the pickup point, $P_{2}$.

Given the proposed NTW layout, the distance function of each addendum has its own zone of applicability. Follow that the zone of applicability of the dual command distance function is the intersection among the three zones of applicability of the two single command functions and the travel between function. Varying the position of $P_{1}$ and $P_{2}$ in the normalised dimensionless space (see Fig. 2 and assumption 4), 17 feasible combinations of the aforementioned distance functions appear. Table 2 schematically presents them. A tick in a cell of the table means a feasible dual command cycle made of (1) the drop-off single command distance function on the left-side row headings, (2) the travel between distance function on the column headings and (3) the last single command distance function on the right-side row headings.

As example, the tick on the top-left side of Table 2 refers to a dual command distance function connecting the $P \& D$ point to $P_{1}$ by $f_{Z_{1}}^{S C}\left(x_{1}, y_{1}, \alpha\right)$, travelling from $P_{1}$ to $P_{2}$ by $f_{Z_{a}}^{T B}\left(x_{1}\right.$ $\left., y_{1}, x_{2}, y_{2}, \alpha\right)$ and moving back to the $\mathrm{P} \& \mathrm{D}$ point by $f_{Z_{1}}^{S C}\left(x_{2}\right.$ $\left., y_{2}, \alpha\right)$. Analytically:

$$
\begin{aligned}
f_{Z_{1} \cap Z_{a} \cap Z_{1}}^{D C}\left(x_{1}, y_{1}, x_{2}, y_{2}, \alpha\right)= & f_{Z_{1}}^{S C}\left(x_{1}, y_{1}, \alpha\right) \\
& +f_{Z a}^{T B}\left(x_{1}, y_{1}, x_{2}, y_{2}, \alpha\right) \\
& +f_{Z_{1}}^{S C}\left(x_{2}, y_{2}, \alpha\right)
\end{aligned}
$$

where the zone of applicability of the dual command distance function is the intersection among the three zones of applicability of its addenda.

Extending the approach adopted by Bortolini et al. [19] for the single command model, shortly recapped in Section 3.1, the application of the Integral Mean Value Theorem allows computing the average dual command distance, $E^{D C}(\alpha)$, as a function of the angle $\alpha$, i.e. the position of the couple of symmetric straight diagonal cross-aisles.

$$
E^{D C}(\alpha)=\frac{1}{A^{2}} \sum_{i=1}^{3} \sum_{j=a}^{\mathrm{e}} \sum_{k=1}^{3} \int_{Z_{i}} \int_{Z_{j}} \int_{Z_{k}} f_{Z_{i} \cap Z_{j} \cap Z_{k}}^{D C}\left(x_{1}, y_{1}, x_{2}, y_{2}, \alpha\right) d Z_{k} d Z_{j} d Z_{i}
$$

In Eq. 12, all addenda with $Z_{i} \cap Z_{j} \cap Z_{k}=\varnothing$ correspond to a combination that does not exist in Table 2. The fulldeveloped closed-form expression of Eq. 12 is omitted for brevity, while its optimisation and the obtained results are discussed in Section 4.

\section{Layout optimisation and discussion}

The single and dual command models for the proposed NTW layout are coded in MAPLE® environment to speed the manipulation of the equations. The Sequential Quadratic Programming (SQP) numerical optimisation algorithm allows minimising the travelled distances, best positioning the couple of symmetric straight diagonal cross-aisles [46]. For this instance, the SQP algorithm convergence is after up to ten seconds using an Intel ${ }^{\circledR}$ CoreTM i7-3770 CPU @ 3.40 GHz and 16.0 GB RAM workstation.

\subsection{Single and dual command cycle optima}

At first, single and dual command cycle distances are minimised, separately, using Eqs. 5 and 12. The former leads to a minimum travel distance of about $E_{\text {opt }}^{S C}=1.70$ per single command cycle, in the dimensionless normalised NTW space when $\alpha_{\text {opt }}^{S C}=34.85^{\circ}$, the latter allows getting a minimum travel distance of about $E_{\text {opt }}^{D C}=2.91$ per dual command cycle, in the dimensionless normalised NTW space when $\alpha_{o p t}^{D C}=30.80^{\circ}$. These results suggest to optimally positioning the couple of symmetric straight diagonal cross-aisles according to the best angles, slightly different for single and dual command cycles. In addition, because of two single command cycles allow getting the same throughput of each dual command cycle, the full adoption of dual command operations leads to an average distance saving of about $14.41 \%$.

Finally, the net benefit of adopting the proposed NTW layout with a couple of symmetric straight diagonal crossaisles toward the standard reference layout with parallel vertical racks follows from the comparison of the obtained results and those coming from $E^{S C}(\alpha)$ and $E^{D C}(\alpha)$ when $\alpha=0$, i.e. no diagonal cross-aisle. This comparison is in Table 3.

The proposed NTW outperforms the standard layout with no diagonal cross-aisles for both single and dual command cycles. Nevertheless, in the proposed NTW, single and dual command cycle distances are minimised for different values of the $\alpha$ angle. In practice, because of this angle defines the position of the couple of symmetric straight diagonal crossaisles, it cannot be changed once the NTW is built, despite the 
Table 2 Dual command distance function, feasible combinations

\begin{tabular}{|c|c|c|c|c|c|c|}
\hline \multirow{2}{*}{$\begin{array}{l}\text { Single } \\
\text { command } \\
P \& D \rightarrow P_{1}\end{array}$} & \multicolumn{5}{|c|}{ Travel between $P_{1} \rightarrow P_{2}$} & \multirow{2}{*}{$\begin{array}{l}\text { Single } \\
\text { command } \\
P_{2} \rightarrow P \& D\end{array}$} \\
\hline & $f_{Z_{a}}^{T B}$ & $f_{Z_{b}}^{T B}$ & $f_{Z_{c}}^{T B}$ & $f_{Z_{d}}^{T B}$ & $f_{Z_{e}}^{T B}$ & \\
\hline \multirow[t]{3}{*}{$f_{Z_{1}}^{S C}$} & $\checkmark$ & & $\checkmark$ & & & $f_{Z_{1}}^{S C}$ \\
\hline & $\checkmark$ & & $\checkmark$ & $\checkmark$ & & $f_{Z_{2}}^{S C}$ \\
\hline & & & $\checkmark$ & $\checkmark$ & & $f_{Z_{3}}^{S C}$ \\
\hline \multirow[t]{3}{*}{$f_{Z_{2}}^{S C}$} & $\checkmark$ & & $\checkmark$ & & $\checkmark$ & $f_{Z_{1}}^{S C}$ \\
\hline & & & $\checkmark$ & & & $f_{Z_{2}}^{S C}$ \\
\hline & & & $\checkmark$ & & & $f_{Z_{3}}^{S C}$ \\
\hline \multirow[t]{3}{*}{$f_{Z_{3}}^{S C}$} & & & $\checkmark$ & & $\checkmark$ & $f_{Z_{1}}^{S C}$ \\
\hline & & & $\checkmark$ & & & $f_{Z_{2}}^{S C}$ \\
\hline & & $\checkmark$ & $\checkmark$ & & & $f_{Z_{3}}^{S C}$ \\
\hline
\end{tabular}

incidence of single and dual command cycles may vary over time. In the following, this point is fixed integrating single and dual command operations.

\subsection{Single and dual command cycle integration}

In common warehouse operations, single and dual command cycles coexist to address the UL S/R activities. In some operative contexts, the ratio between the two types of command cycles is almost constant over time. Under this hypothesis, the optimisation of the NTW layout is possible getting the best value of $\alpha$ minimising the weighted average travel distance of single and dual command operations (the weight is the incidence of each type of cycle). Adopting a resolution of 5\%, Fig. 5 shows $\alpha_{\text {opt }}$ varying the percentage of dual command cycles, from $0 \%$ - single command cycles, only, to $100 \%$ dual command cycles, only.

Globally, the range of variation of the optimal angle is up to $4.5^{\circ}$. This evidence points out a mid-low dependence of the NTW layout on the adopted UL S/R operation mode. Section 5 applies the model to an industrial case study linking the equations to the industrial practice.

\section{Case study}

The investigated industrial scenario is for an Italian mid-size company operating in the sector of long life food and beverage (major information is omitted because confidential). The AsIs configuration of the storage system is of about $106.1 \times 52.1$ m, with 18 aisles, 6 vertical levels, 18 spans per aisle and 3 bays per span with racks for ISO1 Eur-Epal ULs. The dimensionless area is of about $A \approx 2.036$, close to the reference value of two stated in assumption 4, making the proposed model applicable with acceptable approximation. Difference is due to the non-continuity, i.e. discrete, of the space, racks and aisles and the presence of structural constraints, e.g. pillars, walls, etc. The $P \& D$ point is located in the lower centre of the front. The storage assignment policy is random and no diagonal cross-aisle is included. Starting from this scenario, the proposed model is applied investigating the benefit of the inclusion of a couple of optimally oriented symmetric straight diagonal cross-aisles, as in Fig. 1. The target throughput, considering all the $\mathrm{S} / \mathrm{R}$ activities, is of about 140,800 ULs per year to store or retrieve.

\subsection{Layout design and annual distance savings}

Because of the incidence of single and dual command cycles in the case study scenario is almost undefined, multiple configurations are assessed following the approach presented in Section 4.2. For each case, the position of the couple of symmetric straight diagonal cross-aisles, defining the NTW layout, is according to the optimal value of the angle $\alpha$. Figure 6 compares the annual travelled distances between the NTW and the standard layout, matching the company target throughput.

The positive impact of the NTW layout in the reduction of the travelled distances increases almost linearly

Table 3 NTW vs. standard layout, average distances and savings

\begin{tabular}{llll}
\hline & NTW layout & Standard layout & Savings \\
\hline Single command cycle, $E^{S C}(\alpha)$ & $1.70\left(\alpha_{\text {opt }}^{S C}=34.85^{\circ}\right)$ & $2.00\left(\alpha^{S C}=0^{\circ}\right)$ & $15.00 \%$ \\
Dual command cycle, $E^{D C}(\alpha)$ & $2.91\left(\alpha_{\text {opt }}^{D C}=30.80^{\circ}\right)$ & $3.67\left(\alpha^{D C}=0^{\circ}\right)$ & $20.71 \%$ \\
\hline
\end{tabular}




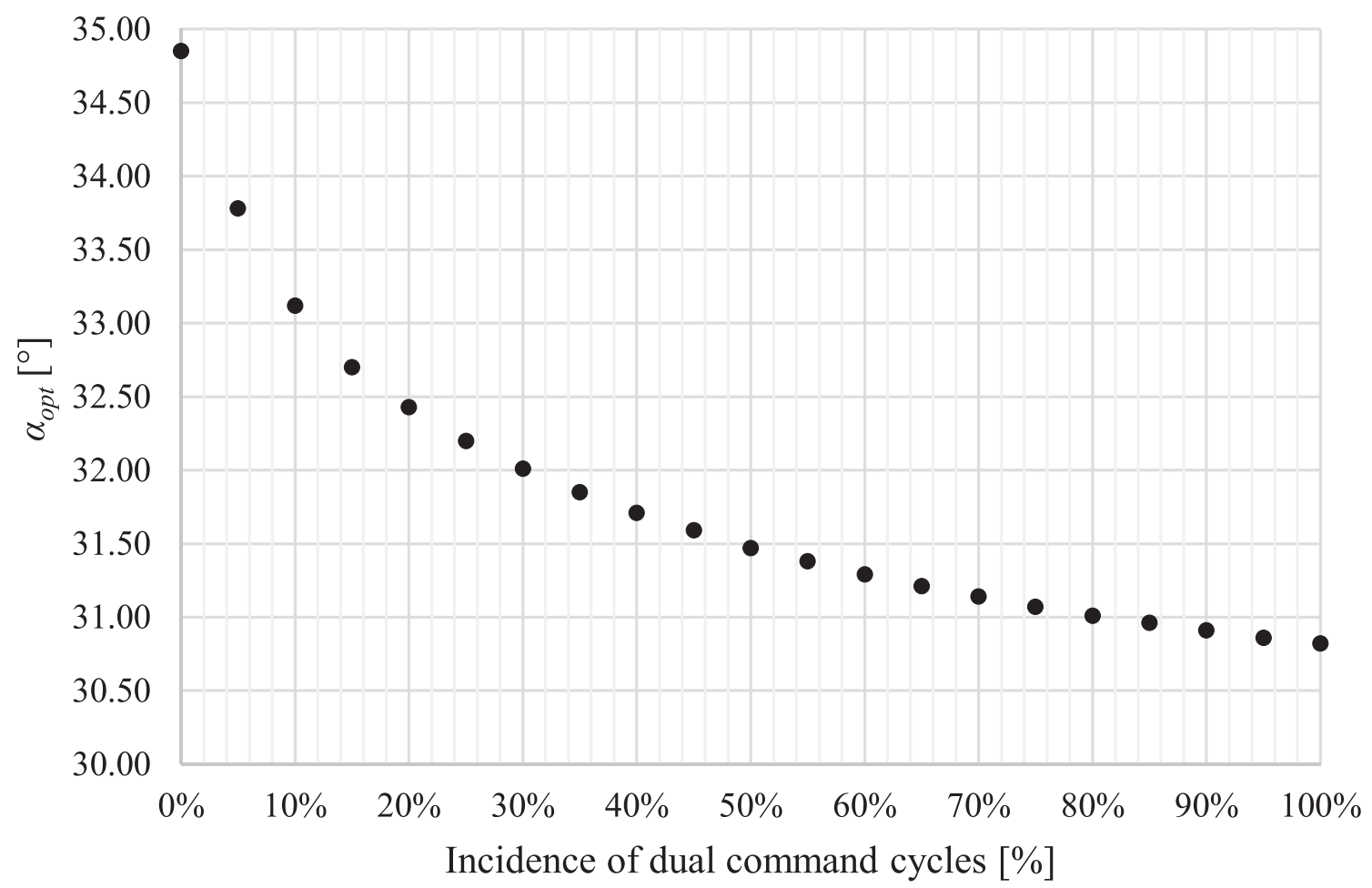

Fig. $5 \alpha_{\text {opt }}$ trend varying the incidence of single and dual command cycles

moving from the single command cycle adoption to the dual command cycle adoption. It ranges between 2175 $\mathrm{km} /$ year and $2800 \mathrm{~km} /$ year.

Finally, because of the value of $\alpha$ has to be chosen during the warehouse design phase and cannot be changed frequently over time, the company analysts based their choice on past data on the frequency of single and dual command cycles. For the considered industrial scenario, the reference incidence of dual command operations is of about $45 \%$ of the total handlings, suggesting to best positioning the couple of symmetric straight diagonal cross-aisles using $\alpha=31.59^{\circ}$, according to the results of Fig. 5. Given the NTW layout, Fig. 7 compares the annual distance savings for the same scenarios of Fig. 6, i.e. varying the incidence of the dual command cycles, between the optimally oriented diagonal cross-aisles (the green bars of Fig. 6) and the warehouse configuration using $\alpha=31.59^{\circ}$ for all scenarios.

As expected, the adoption of $\alpha=31.59^{\circ}$ for all scenarios, matching the operative constraints forcing not to be able to change the diagonal cross-aisle position continuously, worsen the performances toward the optimally oriented case. Nevertheless, the distance saving maximum decrease is of about $1.45 \%$, i.e. $~ 40 \mathrm{~km} / \mathrm{year}$, in the $100 \%$ dual command scenario supporting the general conclusion of a slight dependence of the $\alpha$ angle on the single and dual command cycle combination.

\subsection{Loss of storage space}

In NTWs, the presence of the additional aisles leads to a reduction of the available storage area due to the presence of these paths. Bortolini et al. [19] discussed this topic presenting a quantitative model to estimate the loss of space for the NTW of Fig. 1. Despite the wide discussion of this model is out of scope for this paper, Eq. 13 is the reference expression to compute the relative storage capacity loss due to the presence of a diagonal cross-aisle oriented according to the $\alpha$ angle.

$S C_{\text {loss }}(\alpha)=\frac{2 \cdot l+i \cdot \sin \alpha}{2 \cdot H \cdot \cos \alpha}$

where $H$ is the storage area depth (m), $i$ is the width of the racks $(\mathrm{m})$ and $l$ is the aisle width (m).

Given $S C_{\text {loss }}(\alpha)$, its impact on the travelled distances is obtained scaling the standard reference layout, with no diagonal cross-aisles, as in Eq. 14, making the NTW and the standard warehouse comparable in terms of net storage capacity [19].

$E_{\text {net }}^{S C / D C}\left(\alpha=0^{\circ}\right)=E^{S C / D C}\left(\alpha=0^{\circ}\right) \cdot \sqrt{1-S C_{\text {loss }}(\alpha)}$

where the subscript net means after the inclusion of the storage space loss.

Within the investigated industrial scenario, $i=2.5 \mathrm{~m}$ and $l=3 \mathrm{~m}$, while the storage area depth is $H=52.1 \mathrm{~m}$. Given, $\alpha=$ $31.59^{\circ}$ the relative storage capacity loss is of about $8.24 \%$. 


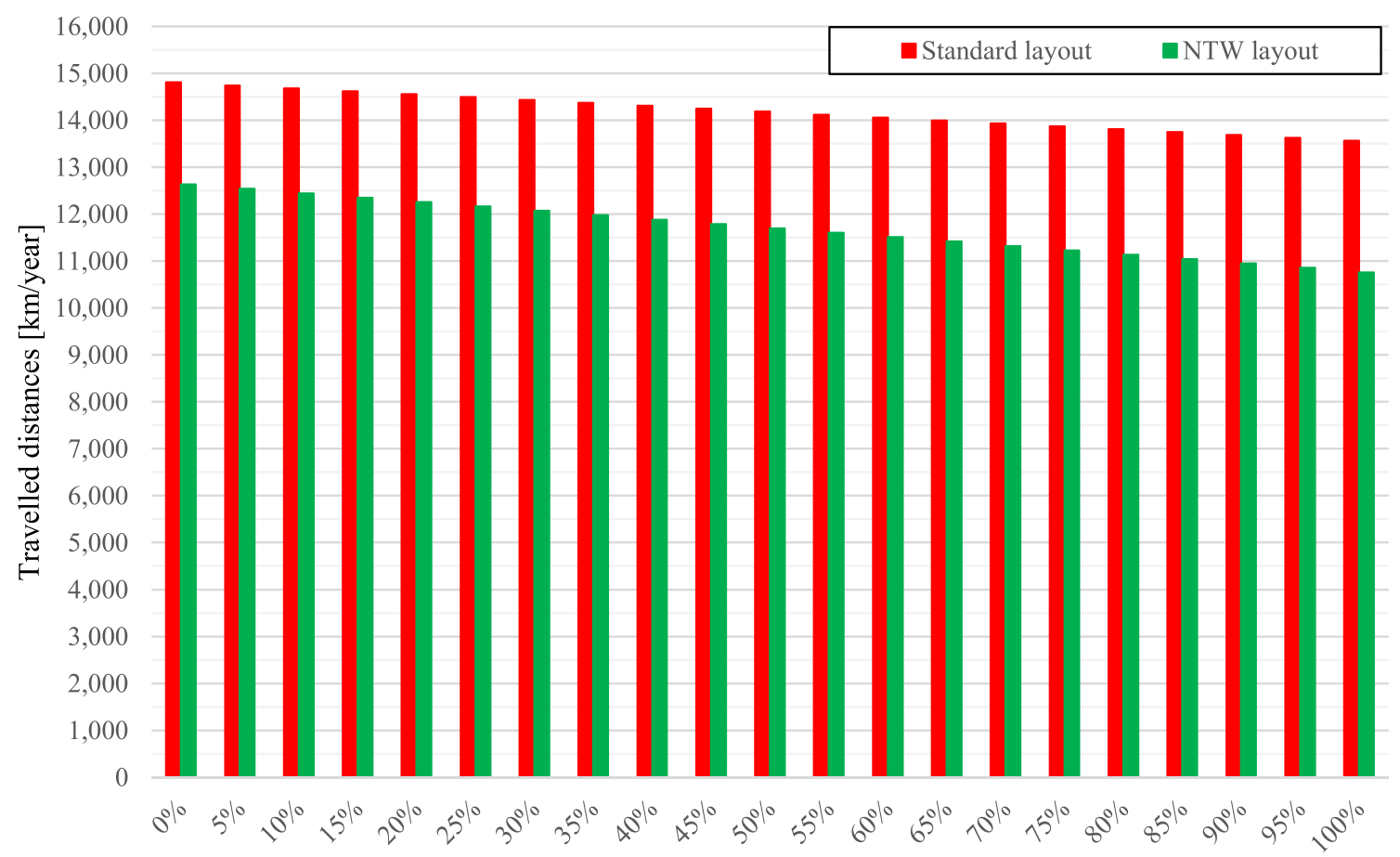

Incidence of dual command cycles [\%]

Fig. 6 Case study, comparison of the annual travelled distances

Figure 8 presents the annual distance savings, adopting the chosen position of the couple of symmetric straight diagonal cross-aisles and including the storage space loss.
Results highlights, on average, a net decrease of about $1866 \mathrm{~km} /$ year. The percentage reduction of the travelled distances is between 11 and $17 \%$ according to the incidence of

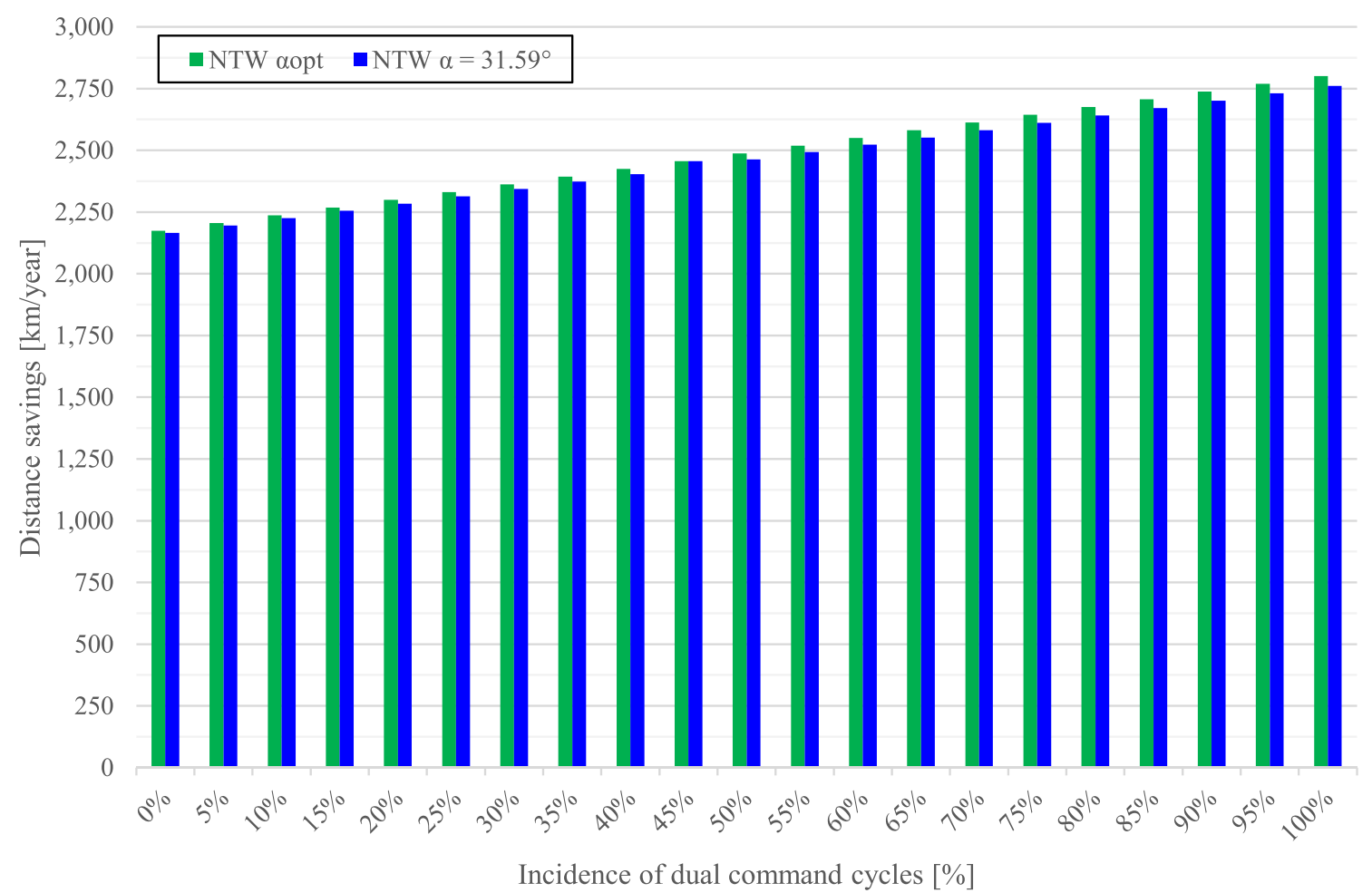

Fig. 7 Case study, impact of NTW diagonal cross-aisle final positioning 
the single and the dual command operations and due to the adoption of the proposed NTW layout.

\section{Conclusions and future research}

This paper extends the existing research on nontraditional warehouses (NTWs), known as feasible and potentially useful solutions to optimise the inbound handling activities within unit-load (UL) storage systems. A NTW layout configuration with parallel vertical racks and a couple of straight diagonal cross-aisles departing from the central pickup and delivery (P\&D) point is focused presenting and applying the analytic models to integrate single and dual command operations, getting the expressions to compute the average travelled distances for the UL storage and retrieval (S/R).

Previous research provides the closed-form expression for single command operations [19]. This paper expands the approach to dual command cycles and to any combination of single and dual command cycles optimising the position of the diagonal cross-aisles under the UL randomised assignment policy.

Results highlight a slight dependence of the optimal orientation of the couple of straight diagonal cross-aisles on the adopted combination of single and dual command operations. The range of variation of the optimal angle between the warehouse front and the diagonal cross-aisle position is from $30.80^{\circ}$ to $34.85^{\circ}$. Additionally, the NTW layout allows distance savings per cycle from $15 \%$ up to $21 \%$. Saving increases if the incidence of dual command operations increases.

Finally, an industrial case study provides a first application of the proposed model to the operative environment. Given the storage system dimensions and the expected annual throughput, the design and optimisation of the NTW layout is proposed. A comparative analysis between the standard and the NTW storage system allows concluding of a potential distance saving in the range between 11 and $17 \%$, varying the single and dual command frequency and considering the loss of space due to the presence of the couple of straight diagonal crossaisles. This saving corresponds, on average, to a decrease of about $1866 \mathrm{~km} /$ year of the inbound travelled distances.

Future research includes extensions of the proposed model to overcome some of the adopted assumptions. Class-based storage assignment policy, the inclusion of vertical distances and different shape factors are research streams of certain interest. In addition, the impact of multiple P\&D points can be studied. Lastly, applications to other industrial contexts to spread the transition from research to practice are welcomed.

Funding Open access funding provided by Alma Mater Studiorum Università di Bologna within the CRUI-CARE Agreement.

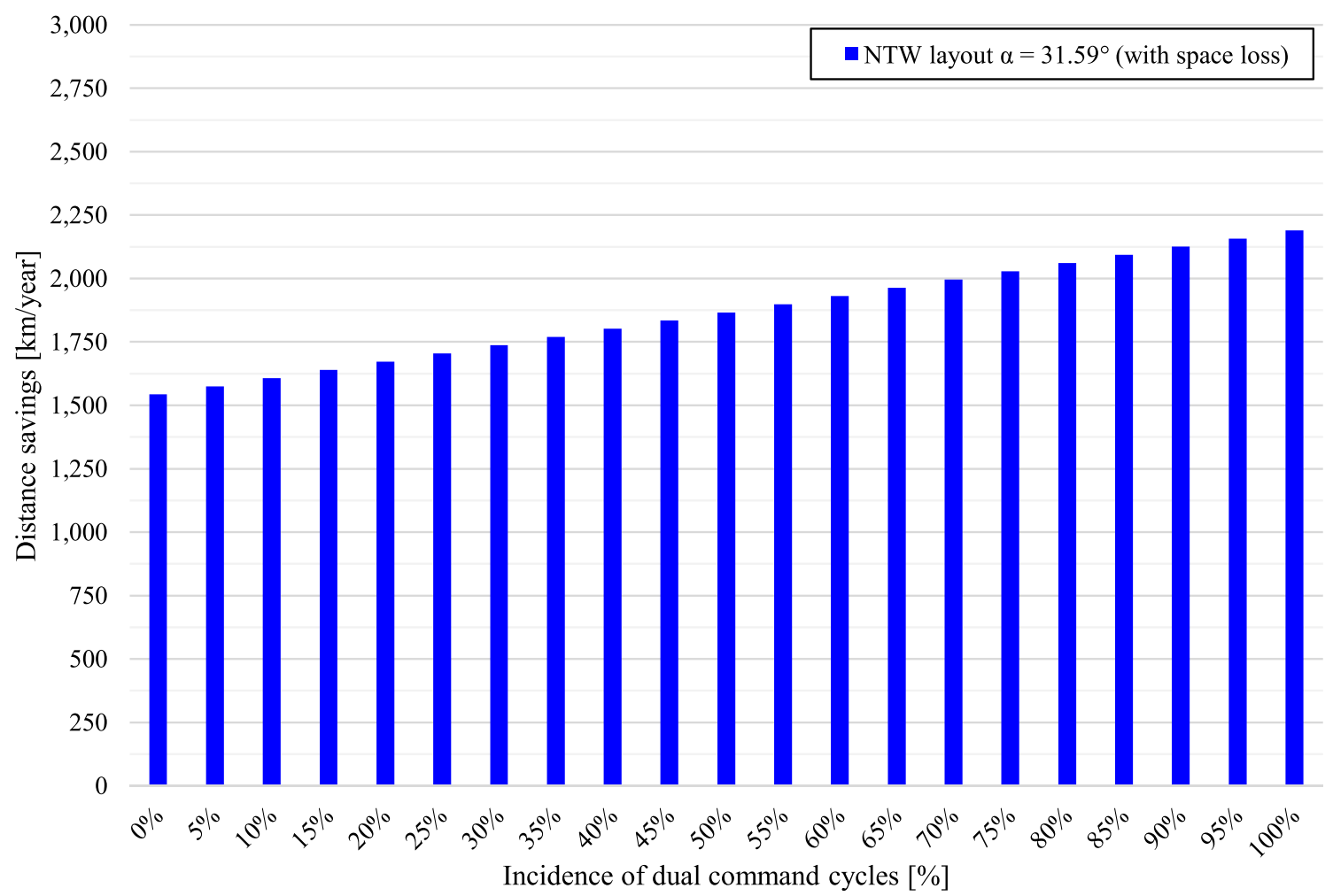

Fig. 8 Case study, annual distance savings including the storage space loss 


\section{Appendix}

Travel between paths. Analytic formulations of $Z_{j}$ for the five reference cases of Fig. 4.

$$
\begin{aligned}
& \left\{\begin{array} { c } 
{ 0 \leq x _ { 1 } \leq 1 } \\
{ x _ { 1 } \leq x _ { 2 } \leq 1 } \\
{ 0 \leq y _ { 1 } < x _ { 1 } \cdot \operatorname { t a n } \alpha } \\
{ 0 \leq y _ { 2 } < \rho _ { a c } }
\end{array} \cup \left\{\begin{array} { c } 
{ - 1 \leq x _ { 1 } < 0 } \\
{ - 1 \leq x _ { 2 } \leq x _ { 1 } } \\
{ 0 \leq y _ { 1 } < x _ { 1 } \cdot \operatorname { t a n } \alpha } \\
{ 0 \leq y _ { 2 } < \rho _ { a c } }
\end{array} \cup \{ \begin{array} { c } 
{ 0 \leq x _ { 1 } \leq 1 } \\
{ 0 \leq x _ { 2 } < x _ { 1 } } \\
{ 0 \leq y _ { 1 } < x _ { 1 } \cdot \operatorname { t a n } \alpha } \\
{ 0 \leq y _ { 2 } < \rho _ { a c } ^ { \prime } }
\end{array} \} \left\{\begin{array}{c}
-1 \leq x_{1}<0 \\
x_{1}<x_{2}<0 \\
0 \leq y_{1}<x_{1} \cdot \tan \alpha \\
0 \leq y_{2}<\rho_{a c}^{\prime}
\end{array}\right.\right.\right. \\
& \cup\left\{\begin{array} { c } 
{ - 1 \leq x _ { 1 } < 0 } \\
{ 0 \leq x _ { 2 } \leq 1 } \\
{ 0 \leq y _ { 1 } < x _ { 1 } \cdot \operatorname { t a n } \phi } \\
{ 0 \leq y _ { 2 } < x _ { 2 } \cdot \operatorname { t a n } \phi }
\end{array} \cup \left\{\begin{array}{c}
0 \leq x_{1} \leq 1 \\
-1 \leq x_{2}<0 \\
0 \leq y_{1}<x_{1} \cdot \tan \phi \\
0 \leq y_{2}<x_{2} \cdot \tan \phi
\end{array}\right.\right.
\end{aligned}
$$

where $\rho_{a c}$ and $\rho_{a c}^{\prime}$ extend to the $A \times A$ hyperspace the isodistance lines already introduced for the single command model. They are obtained by equating Eqs. 6 and 8. $\rho_{a c}$ is used if $P_{1}$ is closer to the P\&D point respect to $P_{2}$, while $\rho_{a c}^{\prime}$ is used in the opposite case. Analytically:

$\rho_{a c}: y_{2}=-y_{1}+\operatorname{abs}\left(x_{2}-x_{1}\right) \cdot \tan \phi+\operatorname{abs}\left(x_{1}\right) \cdot \tan \alpha$

$\rho_{a c}: y_{2}=-y_{1}+\operatorname{abs}\left(x_{2}-x_{1}\right) \cdot \tan \phi+\operatorname{abs}\left(x_{2}\right) \cdot \tan \alpha$

$$
\begin{gathered}
\left\{\begin{array}{c}
0 \leq x_{1} \leq 1 \\
x_{1} \leq x_{2} \leq 1 \\
x_{1} \cdot \tan \alpha \leq y_{1} \leq 1 \\
\chi_{b c}<y_{2} \leq 1
\end{array}\right. \\
\qquad\left\{\begin{array}{c}
-1 \leq x_{1}<0 \\
-1 \leq x_{2} \leq x_{1} \\
x_{1} \cdot \tan \alpha \leq y_{1} \leq 1 \\
\chi_{b c}<y_{2} \leq 1
\end{array}\right. \\
\end{gathered}
$$

where $\chi_{b c}$ and $\chi_{b c}^{\prime}$ are the hyperspace extension of the isodistance lines obtained by equating Eqs. 7 and 8. If $P_{1}$ and $P_{2}$ are in the same half side of the storage system respect to the $y$-axis, $\chi_{b c}$ is used if $P_{1}$ is closer to the $\mathrm{P} \& \mathrm{D}$ point respect to $P_{2}$, while $\chi_{b c}^{\prime}$ is used in the opposite case. If $P_{1}$ and $P_{2}$ are in the opposite sides of the storage system respect to the $y$-axis, $\xi_{b c}$ is used. Analytically:

$$
\begin{gathered}
\chi_{b c}=1-y_{1}+\operatorname{abs}\left(x_{2}-x_{1}\right) \cdot \tan \phi+\operatorname{abs}\left(x_{2}\right) \cdot \tan \alpha \\
\chi_{b c}=1-y_{1}+\operatorname{abs}\left(x_{2}-x_{1}\right) \cdot \tan \phi+\operatorname{abs}\left(x_{1}\right) \cdot \tan \alpha \\
\xi_{b c}=1-y_{1}+\operatorname{abs}\left(x_{2}-x_{1}\right) \cdot \tan \phi+\operatorname{abs}\left(x_{2}-x_{1}\right) \cdot \tan \alpha
\end{gathered}
$$

Zone $c$ 


$$
\begin{aligned}
& \left\{\begin{array} { c } 
{ 0 \leq x _ { 1 } \leq 1 } \\
{ x _ { 1 } \leq x _ { 2 } \leq 1 } \\
{ 0 \leq y _ { 1 } < x _ { 1 } \cdot \operatorname { t a n } \alpha } \\
{ \rho _ { a c } \leq y _ { 2 } < x _ { 2 } \cdot \operatorname { t a n } \alpha }
\end{array} \cup \left\{\begin{array} { c } 
{ - 1 \leq x _ { 1 } < 0 } \\
{ - 1 \leq x _ { 2 } \leq x _ { 1 } } \\
{ 0 \leq y _ { 1 } < x _ { 1 } \cdot \operatorname { t a n } \alpha } \\
{ \rho _ { a c } \leq y _ { 2 } < x _ { 2 } \cdot \operatorname { t a n } \alpha }
\end{array} \cup \left\{\begin{array}{c}
0 \leq x_{1} \leq 1 \\
0 \leq x_{2}<x_{1} \\
0 \leq y_{1}<x_{1} \cdot \tan \alpha \\
\rho_{a c}^{\prime} \leq y_{2}<x_{2} \cdot \tan \alpha
\end{array}\right.\right.\right. \\
& \cup\left\{\begin{array} { c } 
{ - 1 \leq x _ { 1 } < 0 } \\
{ x _ { 1 } < x _ { 2 } < 0 } \\
{ 0 \leq y _ { 1 } < x _ { 1 } \cdot \operatorname { t a n } \alpha } \\
{ \rho _ { a c } ^ { \prime } \leq y _ { 2 } < x _ { 2 } \cdot \operatorname { t a n } \alpha }
\end{array} \cup \left\{\begin{array} { c } 
{ 0 \leq x _ { 1 } \leq 1 } \\
{ x _ { 1 } \leq x _ { 2 } \leq 1 } \\
{ x _ { 1 } \cdot \operatorname { t a n } \alpha \leq y _ { 1 } \leq 1 } \\
{ x _ { 2 } \cdot \operatorname { t a n } \alpha \leq y _ { 2 } \leq \chi _ { b c } }
\end{array} \cup \left\{\begin{array}{c}
-1 \leq x_{1} \leq 0 \\
-1 \leq x_{2} \leq x_{1} \\
x_{1} \cdot \tan \alpha \leq y_{1} \leq 1 \\
x_{2} \cdot \tan \alpha \leq y_{2} \leq \chi_{b c}
\end{array}\right.\right.\right. \\
& \cup\left\{\begin{array} { c } 
{ 0 \leq x _ { 1 } \leq 1 } \\
{ 0 \leq x _ { 2 } < x _ { 1 } } \\
{ x _ { 1 } \cdot \operatorname { t a n } \alpha \leq y _ { 1 } \leq 1 } \\
{ x _ { 2 } \cdot \operatorname { t a n } \alpha \leq y _ { 2 } \leq \chi _ { b c } ^ { \prime } }
\end{array} \cup \left\{\begin{array} { c } 
{ - 1 \leq x _ { 1 } < 0 } \\
{ x _ { 1 } < x _ { 2 } < 0 } \\
{ x _ { 1 } \cdot \operatorname { t a n } \alpha \leq y _ { 1 } \leq 1 } \\
{ x _ { 2 } \cdot \operatorname { t a n } \alpha \leq y _ { 2 } \leq \chi _ { b c } ^ { \prime } }
\end{array} \cup \left\{\begin{array}{c}
-1 \leq x_{1}<0 \\
0 \leq x_{2} \leq 1 \\
x_{1} \cdot \tan \alpha \leq y_{1} \leq 1 \\
x_{2} \cdot \tan \alpha \leq y_{2} \leq \xi_{b c}
\end{array}\right.\right.\right. \\
& \cup\left\{\begin{array} { c } 
{ 0 \leq x _ { 1 } \leq 1 } \\
{ - 1 \leq x _ { 2 } < 0 } \\
{ x _ { 1 } \cdot \operatorname { t a n } \alpha \leq y _ { 1 } \leq 1 } \\
{ x _ { 2 } \cdot \operatorname { t a n } \alpha \leq y _ { 2 } \leq \xi _ { b c } }
\end{array} \cup \left\{\begin{array} { c } 
{ 0 \leq x _ { 1 } \leq 1 } \\
{ 0 \leq x _ { 2 } \leq 1 } \\
{ 0 \leq y _ { 1 } < x _ { 1 } \cdot \operatorname { t a n } \alpha } \\
{ x _ { 2 } \cdot \operatorname { t a n } \alpha \leq y _ { 2 } \leq 1 }
\end{array} \cup \left\{\begin{array}{c}
0 \leq x_{1} \leq 1 \\
0 \leq x_{2} \leq 1 \\
x_{1} \cdot \tan \alpha<y_{1} \leq 1 \\
0 \leq y_{2}<x_{2} \cdot \tan \alpha
\end{array}\right.\right.\right. \\
& \cup\left\{\begin{array} { c } 
{ - 1 \leq x _ { 1 } < 0 } \\
{ - 1 \leq x _ { 2 } < 0 } \\
{ 0 \leq y _ { 1 } < x _ { 1 } \cdot \operatorname { t a n } \alpha } \\
{ x _ { 2 } \cdot \operatorname { t a n } \alpha \leq y _ { 2 } \leq 1 }
\end{array} \cup \left\{\begin{array} { c } 
{ - 1 \leq x _ { 1 } < 0 } \\
{ - 1 \leq x _ { 2 } < 0 } \\
{ x _ { 1 } \cdot \operatorname { t a n } \alpha \leq y _ { 1 } \leq 1 } \\
{ 0 \leq y _ { 2 } < x _ { 2 } \cdot \operatorname { t a n } \alpha }
\end{array} \cup \left\{\begin{array}{c}
0 \leq x_{1} \leq 1 \\
-1 \leq x_{2} \leq 0 \\
x_{1} \cdot \tan \phi \leq y_{1}<x_{1} \cdot \tan \alpha \\
x_{2} \cdot \tan \phi \leq y_{2}<x_{2} \cdot \tan \alpha
\end{array}\right.\right.\right. \\
& \cup\left\{\begin{array} { c } 
{ - 1 \leq x _ { 1 } \leq 0 } \\
{ 0 \leq x _ { 2 } \leq 1 } \\
{ x _ { 1 } \cdot \operatorname { t a n } \phi \leq y _ { 1 } < x _ { 1 } \cdot \operatorname { t a n } \alpha } \\
{ x _ { 2 } \cdot \operatorname { t a n } \phi < y _ { 2 } < x _ { 2 } \cdot \operatorname { t a n } \alpha }
\end{array} \cup \left\{\begin{array} { c } 
{ - 1 \leq x _ { 1 } \leq 0 } \\
{ 0 \leq x _ { 2 } \leq 1 } \\
{ x _ { 1 } \cdot \operatorname { t a n } \alpha \leq y _ { 1 } \leq 1 } \\
{ x _ { 2 } \cdot \operatorname { t a n } \phi < y _ { 2 } < x _ { 2 } \cdot \operatorname { t a n } \alpha }
\end{array} \cup \left\{\begin{array}{c}
0 \leq x_{1} \leq 1 \\
-1 \leq x_{2} \leq 0 \\
x_{1} \cdot \tan \phi<y_{1} \leq x_{1} \cdot \tan \alpha \\
x_{2} \cdot \tan \alpha<y_{2}<1
\end{array}\right.\right.\right. \\
& \cup\left\{\begin{array} { c } 
{ - 1 \leq x _ { 1 } < 0 } \\
{ 0 \leq x _ { 2 } < 1 } \\
{ x _ { 1 } \cdot \operatorname { t a n } \phi \leq y _ { 1 } < x _ { 1 } \cdot \operatorname { t a n } \alpha } \\
{ x _ { 2 } \cdot \operatorname { t a n } \alpha \leq y _ { 2 } \leq 1 }
\end{array} \cup \left\{\begin{array}{c}
0 \leq x_{1}<1 \\
-1 \leq x_{2}<0 \\
x_{1} \cdot \tan \alpha \leq y_{1} \leq 1 \\
x_{2} \cdot \tan \phi \leq y_{2}<x_{2} \cdot \tan \alpha
\end{array}\right.\right.
\end{aligned}
$$

Zone $d$

$$
\left\{\begin{array}{c}
0 \leq x_{1} \leq 1 \\
-1 \leq x_{2}<0 \\
0 \leq y_{1}<x_{1} \cdot \tan \phi \\
x_{2} \cdot \tan \phi \leq y_{2} \leq 1
\end{array}\right\}\left\{\begin{array}{c}
-1 \leq x_{1}<0 \\
0 \leq x_{2} \leq 1 \\
0 \leq y_{1}<x_{1} \cdot \tan \phi \\
x_{2} \cdot \tan \phi \leq y_{2} \leq 1
\end{array}\right.
$$

Zone $e$

$$
\left\{\begin{array}{c}
0 \leq x_{1} \leq 1 \\
-1 \leq x_{2}<0 \\
x_{1} \cdot \tan \phi \leq y_{1} \leq 1 \\
0 \leq y_{2}<x_{2} \cdot \tan \phi
\end{array}\right\}\left\{\begin{array}{c}
-1 \leq x_{1}<0 \\
0 \leq x_{2} \leq 1 \\
x_{1} \cdot \tan \phi \leq y_{1} \leq 1 \\
0 \leq y_{2}<x_{2} \cdot \tan \phi
\end{array}\right.
$$

Open Access This article is licensed under a Creative Commons Attribution 4.0 International License, which permits use, sharing, adaptation, distribution and reproduction in any medium or format, as long as you give appropriate credit to the original author(s) and the source, provide a link to the Creative Commons licence, and indicate if changes were made. The images or other third party material in this article are included in the article's Creative Commons licence, unless indicated otherwise in a credit line to the material. If material is not included in the article's Creative Commons licence and your intended use is not permitted by statutory regulation or exceeds the permitted use, you will need to obtain permission directly from the copyright holder. To view a copy of this licence, visit http://creativecommons.org/licenses/by/4.0/.

\section{References}

1. Faber N, De Koster R, Smidts A (2013) Organizing warehouse management. Int J Oper Prod Manag 33(9):1230-1256

2. Gue KR, Meller RD (2009) Aisle configurations for unit-load warehouses. IIE Trans 41(3):171-182

3. Richards G (2017) Warehouse management: a complete guide to improving efficiency and minimizing costs in the modern warehouse. Kogan Page Publishers

4. Accorsi R, Bortolini M, Gamberi M, Manzini R, Pilati F (2017) Multi-objective warehouse building design to optimize the cycle time, total cost, and carbon footprint. Int J Adv Manuf Technol 92(1-4):839-854

5. Mustapha M, Hasan F, Shaladdin M (2018) Lean Six Sigma implementation: multiple case studies in a developing country. Int $\mathrm{J}$ Lean Six Sigma 10(1):523-539

6. Pohl LM, Meller RD, Gue KR (2009b) Optimizing Fishbone aisles for dual-command operations in a warehouse. Nav Res Logist (NRL) 56(5):389-403

7. Zhang G, Nishi T, Turner S, Oga K, Li X (2017) An integrated strategy for a production planning and warehouse layout problem: modeling and solution approaches. Omega 68:85-94 
8. Rouwenhorst B, Reuter B, Stockrahm V, van Houtum G, Mantel R, Zijm W (2000) Warehouse design and control: framework and literature review. Eur J Oper Res 122:515-533

9. Gu J, Goetschalckx M, McGinnis L (2010) Research on warehouse design and performance evaluation: a comprehensive review. Eur J Oper Res 203(3):539-549

10. Thomas LM, Meller RD (2014) Analytical models for warehouse configuration. IIE Trans 46(9):928-947

11. Francis RL (1967) On some problems of rectangular warehouse design and layout. J Ind Eng 18(10):595-604

12. Bassan Y, Roll Y, Rosenblatt MJ (1980) Internal layout design of a warehouse. AIIE Trans 12(4):317-322

13. Malmborg CJ, Krishnakumar B (1987) On the optimality of the cube per order index for conventional warehouses with dual command cycles. Mater Flow 4:169-175

14. Malmborg CJ, Krishnakumar B (1990) A revised proof of optimality for the cube-per-order index rule for stored item location. Appl Math Model 14(2):87-95

15. Roodbergen K, De Koster R (2001a) Routing methods for warehouses with multiple cross aisles. Int J Prod Res 39:1865-1883

16. Hedler Staudt F, Alpan G, Di Mascolo M, Rodriguez C (2015) Warehouse performance measurement: a literature review. Int $\mathrm{J}$ Prod Res 53:5524-5544

17. Yener E, Yazgan H (2019) Optimal warehouse design: literature review and case study application. Comput Ind Eng 129:1-13

18. Custodio L, Machado R (2020) Flexible automated warehouse: a literature review and an innovative framework. Int J Adv Manuf Technol 106:533-558

19. Bortolini M, Faccio M, Gamberi M, Manzini R (2015) Diagonal cross-aisles in unit load warehouses to increase handling performance. Int J Prod Econ 170:838-849

20. White JA (1972) Optimum design of warehouses having radial aisles. AIIE Trans 4(4):333-336

21. Pohl LM, Meller RD, Gue KR (2011) Turnover-based storage in non-traditional unit-load warehouse designs. IIE Trans 43:703-720

22. Jiang MX, Feng DZ, Zhao YL, Yu MF (2013) Optimization of logistics warehouse layout based on the improved Fishbone layout. Syst Eng Theory Pract 33:2920-2929

23. Cardona L, Rivera L, Martínez H (2012) Analytical study of the Fishbone Warehouse layout. Int J Log Res Appl 15(6):365-388

24. Öztürkoğlu Ö, Gue KR, Meller RD (2012) Optimal unit-load warehouse designs for single-command operations. IIE Trans 44:459475

25. Mesa A (2016) A methodology to incorporate multiple cross aisles in a non-traditional warehouse layout. Electronic Thesis or Dissertation. Ohio University, 2016. Ohio LINK Electronic Theses and Dissertations Center. 23 Apr 2020

26. Gue KR, Ivanović G, Meller RD (2012) A unit-load warehouse with multiple pickup and deposit points and non-traditional aisles. Transport Res E Log 48:795-806

27. Öztürkoğlu Ö, Gue KR, Meller RD (2014) A constructive aisle design model for unit-load warehouses with multiple pickup and deposit points. Eur J Oper Res 236:382-394

28. Öztürkoğlu Ö (2015) Investigating the robustness of aisles in a nontraditional unit-load warehouse design: leverage. In: 2015 IEEE congress on evolutionary computation (CEC), pp 2230-2236
29. Öztürkoğlu Ö (2016) Effects of varying input and output points on new aisle designs in warehouses. In: 2016 IEEE congress on evolutionary computation (CEC), pp 3925-3932

30. Öztürkoğlu Ö, Kocaman Y, Gümüşoğlu S (2018) Evaluating Chevron aisle design in unit load warehouses with multiple pickup and deposit points. J Fac Eng Archit Gazi Univ 33(3):793-807

31. Kocaman Y, Öztürkoğlu Ö, Gümüșoğlu S (2019) Aisle designs in unit-load warehouses with different flow policies of multiple pickup and deposit points. CEJOR:1-33

32. Hsieh LF, Tsai L (2006) The optimum design of a warehouse system on order picking efficiency. Int J Adv Manuf Technol 28(5-6): 626-637

33. Clark K, Meller RD (2013) Incorporating vertical travel into nontraditional cross aisles for unit-load warehouse designs. IIE Trans 45:1322-1331

34. Accorsi R, Bortolini M, Ferrari E, Gamberi M, Pilati F (2018) Class-based storage warehouse design with diagonal cross-aisle. LogForum 14(1):101-112

35. Bortolini M, Faccio M, Ferrari E, Pilati F (2019) Design of diagonal cross-aisle warehouses with class-based storage assignment strategy. Int J Adv Manuf Technol 100(9-12):2521-2536

36. Pohl LM, Meller RD, Gue KR (2009) An analysis of dualcommand operations in common warehouse designs. Transport Res E Log 45:367-379

37. Pohl LM, Meller RD, Gue KR (2007) An evaluation of two new warehouse aisle designs for dual-command travel. IIE Annual Conference and Expo 2007 - Industrial Engineering's Critical Role in a Flat World - Conference Proceedings, pp 740-745

38. Galvez OD, Ting CJ (2012) Analysis of unit-load warehouses with non-traditional aisles and multiple P\&D points. In: The 13th AsiaPacific conference on industrial engineering and management systems 2011-2021

39. Heskett JL (1963) Cube-Per-Order Index: a key to warehouse stock location. Transp Distrib Manag 3:27-31

40. Kallina C, Lynn J (1976) Application of the Cube-Per-Order Index Rule for Stock Location in a Distribution Warehouse. Interfaces 7(1):37-46

41. Roodbergen K, De Koster R (2001b) Routing order pickers in a warehouse with a middle aisle. Eur J Oper Res 133:32-43

42. Manzini R, Gamberi M, Persona A, Regattieri A (2007) Design of a class-based picker to product order picking system. Int J Adv Manuf Technol 32(7-8):811-821

43. Chen JC, Cheng CH, Huang PB, Wang KJ, Huang CJ, Ting TC (2013) Warehouse management with lean and RFID application: a case study. Int J Adv Manuf Technol 69(1-4):531-542

44. Fontana ME, Cavalcante CAV (2014) Use of Promethee method to determine the best alternative for warehouse storage location assignment. Int J Adv Manuf Technol 70(9-12):1615-1624

45. Venkitasubramony R, Adil GK (2017) Design of an order-picking warehouse factoring vertical travel and space sharing. Int J Adv Manuf Technol 91(5-8):1921-1934

46. Bonnans JF, Gilbert JC, Lemaréchal C, Sagastizabal C (2006) Numerical optimization theoretical and practical aspects. Springer Science \& Business Media

Publisher's note Springer Nature remains neutral with regard to jurisdictional claims in published maps and institutional affiliations. 